\title{
Estimation of the Burden of Iron Deficiency Anemia in France from Iron Intake: Methodological Approach
}

\author{
Juliana De Oliveira Mota ${ }^{1}$, Patrick Tounian ${ }^{2}$, Sandrine Guillou ${ }^{1}$, Fabrice Pierre ${ }^{3}$ and \\ Jeanne-Marie Membré ${ }^{1, *(D)}$ \\ 1 Secalim, INRA, Oniris, Université Bretagne Loire, 44307 Nantes, France \\ 2 Service de nutrition et gastroentérologie pédiatriques, hôpital Trousseau, Sorbonne Université, AP-HP, \\ 75012 Paris, France \\ 3 INRA, ToxAlim (Research Centre in Food Toxicology), Université de Toulouse, INRA, ENVT, INP-Purpan, \\ UPS, 31027 Toulouse, France \\ * Correspondence: jeanne-marie.membre@oniris-nantes.fr; Tel.: +33-240-684-058
}

Received: 24 July 2019; Accepted: 27 August 2019; Published: 1 September 2019

check for updates

\begin{abstract}
Dietary iron deficiency (ID) is the first nutritional deficiency in the world, in terms of disability adjusted life years (DALY). This nutritional deficiency may lead to anemia, especially among children, adolescents, and adult women. The aim of this study was to build an original probabilistic model to quantitatively assess the ID, the iron deficiency anemia (IDA) and the subsequent health burden in France expressed in DALY, per age class and gender. The model considered the distribution of absorbed iron intake, the iron requirement distribution established by the European Food Safety Authority and the iron status in France. Uncertainty due to lack of data and variability due to biological diversity were taken into account and separated using a second-order Monte Carlo procedure. A total of $1290(95 \% \mathrm{CI}=1230-1350)$ IDA cases corresponding to $16(95 \% \mathrm{CI}=11-20)$ DALY were estimated per 100,000 individuals per year. The major contributors to IDA burden were menstruating females aged from 25 to 44 years old. Then, a consumption scenario was built with ground beef as intake, an increase in red meat consumption to $100 \mathrm{~g} / \mathrm{d}$ would not eliminate entirely the IDA burden. The quantitative methodology applied here for France could be reused for other populations.
\end{abstract}

Keywords: iron deficiency; anemia; risk assessment; probabilistic model; second-order Monte Carlo simulation; DALY

\section{Introduction}

The World Health Organization (WHO) estimated that around two billion people were anemic in the world, which makes this disease one of the most common nutrition disorders [1]. Anemia was defined as a hemoglobin $(\mathrm{Hb})$ concentration below the thresholds given by WHO, United Nations Children's Fund (UNICEF), United Nations University (UNU) [2]. For children aged from 6 to 59 months of age and pregnant women, anemia is diagnosed when $\mathrm{Hb}$ is under $11 \mathrm{~g} / \mathrm{dL}$, under $11.5 \mathrm{~g} / \mathrm{dL}$ for children aged 5-11, and under $12 \mathrm{~g} / \mathrm{dL}$ for children aged 12-14 and non-pregnant females. Finally, for males aged 15 years and above, anemia is diagnosed when the level of $\mathrm{Hb}$ is under $13 \mathrm{~g} / \mathrm{dL}$. The main cause of anemia identified was iron deficiency (ID), which is defined by WHO as "a state in which there is insufficient iron to maintain the normal physiological function of tissues such as the blood, brain, and muscles" [1]. ID is characterized by no mobilized iron stores and signs of a compromised supply of iron [3]. ID was estimated to represent over than $60 \%$ of the anemia causes [4,5], especially among the younger population $[4,6]$. This nutritional deficiency-commonly defined as serum ferritin level on blood $\leq 30 \mu \mathrm{g} / \mathrm{L}[7,8]$ - has several consequences for human health, such as a delay in children's mental and physical development, a decrease in work productivity, intelligence or cognitive capacity $[1,9]$. 
In some countries, ID and iron deficiency anemia (IDA) may also contribute to child, maternal, and perinatal mortality [1,9]. Among the overall population, the most concerned by this nutritional disease are children, adolescents, and women (pregnant and non-pregnant) in reproductive age $[4,5,10]$.

To reduce ID, the consumption of bioavailable iron-rich food-such as red meat-would be a logically feasible solution, since this food is the richest source of high absorbable iron (heme-iron) [11]. A study revealed that an increase in red meat consumption twice a week compared to seldom intake would decrease $24 \%$ of child ID in Israel [12]. Another study estimated an increase of $0.6 \%$ in serum ferritin in blood levels per $1 \mathrm{~g}$ of red meat consumed [13].

Since 1990, the Global Burden of Diseases (GBD) study, supported by the World Health Organization, has estimated the disability adjusted life years (DALY) associated with health effects of major diseases, injury, and risk factors. This metric takes into account mortality and morbidity and is expressed as the sum of the number of years of life lost (YLL) from premature death and the number of years lived with disability (YLD) [14]. In addition to quantifying the impact of disease, the burden of diseases helps in risk-mitigating strategy: Several consumption patterns can be evaluated and compared by scenario analysis. In particular, in the study of Kassebaum on behalf of GBD 2013 Anemia Collaborators evaluated the global burden of anemia [4]. This work estimated that, in 2013, anemia was responsible for 61.5 (41.0-88.7) millions of YLD in the world, from which 300,654 (200,463-434,060) YLD in France. However, this burden was estimated from hemoglobin levels, which makes scenarios of iron consumption impossible.

Regarding the separation of uncertainty-due to the lack of data and knowledge and variability associated with heterogeneity within populations- $[15,16]$ of the inputs, it is important to identify which of them are driving the output of the risk model and to identify the needed data to increase the precision and the confidence of the estimated output [17].

The objective of this study was to estimate the burden of disease in France due to ID, taking iron consumption into account. Based upon dietary surveys, iron recommendations and blood iron status of the French population, a probabilistic model was set up for both genders and for specific age classes to quantify the risk of ID and the consequent burden of disease due to IDA. Then, to reduce the burden, consumption scenario was built with ground beef intake as red meat is the richest source of high absorbable iron in developed countries.

\section{Methods}

\subsection{Model Framework for Iron Deficiency Anemia Assessment}

The model was developed for males and females aged from three years old for which the age classes were 3-6, 7-11, 12-17, 18-24, 25-44, 45-64, and 65-74. For female population, the menstruating and menopausal populations were identified as follows: Between 15 and 24 years old, all women are menstruating, between 25 and 64 there are both menstruating and menopausal women and from 65 onwards there are only menopausal women. In addition, for adolescent females, two age classes were identified: 12-14 which were considered non menstruating, and 15-17 which were considered as menstruating.

The flowchart of the risk assessment model is presented in Figure 1. From iron consumption in France, the mean absorption of iron, the iron recommendations, and hemoglobin level in the French population, the number of cases and then the burden of disease per year, gender, and age class were estimated. 


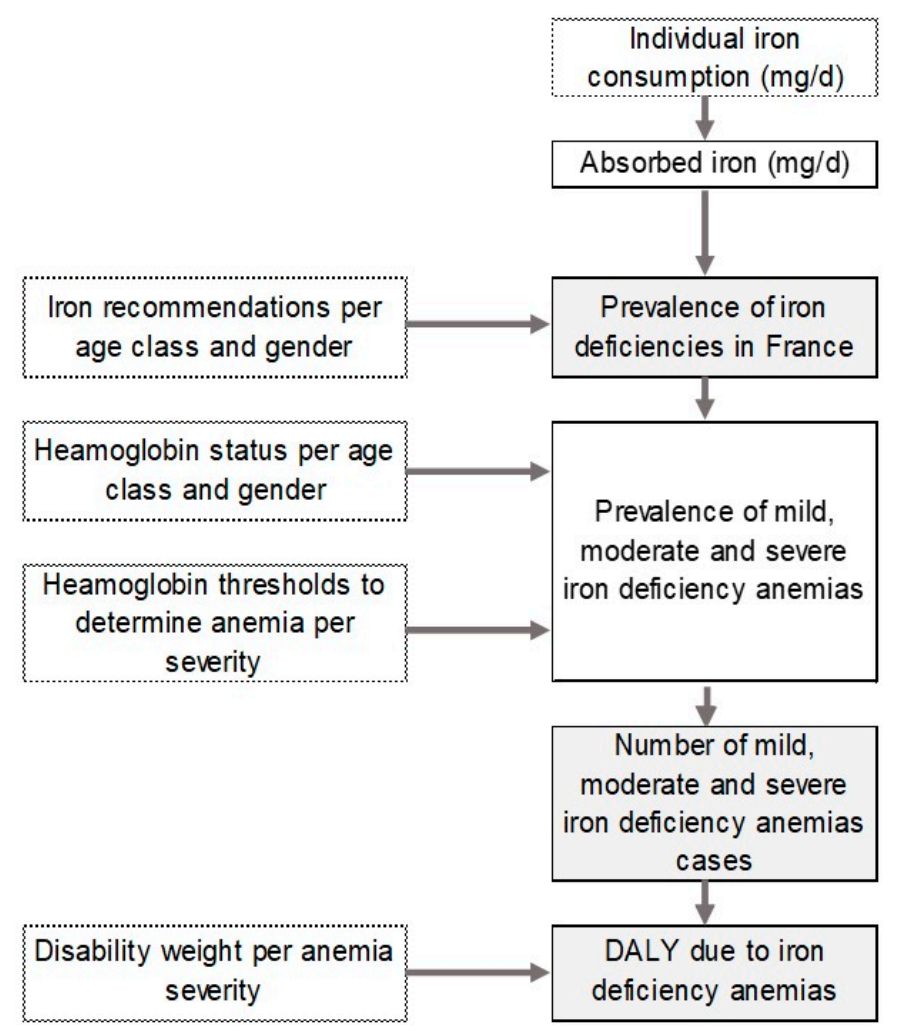

Figure 1. Flowchart of the assessment model of iron deficiency anemia disease per year in France per age class and gender. White rectangles with dashed line correspond to the "Inputs", full line to "Intermediate calculation". Light grey rectangles correspond to the "Final output". Absorbed iron corresponds to the mean absorbed values provided by European Food Safety Authority (EFSA) considering both heme and non-heme iron.

When building the model, several assumptions were made and validated by a medical expert. Three hypotheses were considered:

- ID appears when iron requirements are not covered by dietary iron.

- The ratio between the proportion of ID and IDA remains constant over the consumption scenarios.

- The consumption of bioavailable dietary iron, such as that found in red meat, reduces IDA.

\subsection{Iron Intake Consumption in France}

Iron intake in metropolitan France was evaluated between 2005 and 2007 for males and females aged from 3 to 79, by the dietary survey INCA 2 (approved by the French National Commission for Computed Data and Individual Freedom, "Commission Nationale Informatique et Libertés"; CNIL, under the registration code 797859-v0, on 20 March 2002). From the original data available at https://www.data.gouv.fr/ [18], we selected all-male population and non-pregnant women whose information about pregnancy and menopausal status was available. For unknown status of adult women, this latter was deduced or hypothesized. When the answer about menopausal status was unknown, the pregnancy status was verified. If the latter was negative, the average age of menopausal occurrence was taken into account. Therefore, women aged over 50 years old were assumed menopausal. Women aged less or equal to 50 years old, were assumed pre-menopausal [19]. On the other hand, when pregnancy status was unknown, the menopausal status was verified. If the answer was negative, women were considered as pregnant. Pregnant women were excluded from the study because the number of cases was low for each age class concerned (under 30). Under 18 years old, women were considered not pregnant. From the iron consumed, only a certain amount was absorbed. As for 
European Food Safety Authority (EFSA) estimations, the absorbed iron from iron intake was $10 \%$ for children under 11 years old, $16 \%$ for adolescents and adult males, and $18 \%$ for adult females [20].

To estimate the probability density of iron intake, the function fitdist of the package fitdistrplus was used with the R software version 3.4.0. Based upon the Akaike information criterion (AIC), the lognormal distribution provided the best fit, among Weibull, normal, lognormal and gamma distributions.

\subsection{Prevalence of Iron Deficiency in France}

To calculate ID prevalence in France, iron intake from dietary survey INCA 2 (see Table 1 at "Iron consumption (absorbed)"), was compared with a normal distribution of iron needs, as suggested by the Nordic Council of Ministers in 2014 [21] based on values given by the European Food Safety Authority (EFSA) (2015) [20] (see Table 1 at "Iron needs"). The mean parameter of the normal distribution was the absorbed average requirement value, the standard deviation was the value directly provided by EFSA report, except for males under 17 and females under 14 for which the standard deviation was deduced from the confidence interval upper limit bound of the EFSA report. In the present study, adolescent girls were divided into two groups: Girls from 12 to 14 were considered having not a menstruating status-mean menarcheal age of 13 years old in France [22]—and girls aged from 15 to 17 were assumed to have the iron needs as adult women since all the individuals in this age class were assumed to be menstruating.

The prevalence of people consuming less than the normal probability distribution of the needs was then estimated, using plnorm function of $\mathrm{R}$ software. This population was considered as iron-deficient. By multiplying the prevalence of ID in France by the number of individuals for each age class and gender (see Table 1 at "French population data"), the number of ID cases in France per year was estimated.

\subsection{Prevalence of Iron Deficiency Anemia in France}

Anemia results from levels of hemoglobin $<12-15 \mathrm{~g} / \mathrm{dL}$ and $51 \%(21 \%-85 \%)$ of anemia is due to ID $[10,12,23]$. To estimate IDA prevalence from iron deficiency, we based our calculations on the reported iron deficiencies, iron deficiencies anemias, and anemias from three studies [24-26]. From ID, IDA were calculated as follows:

$$
\text { Prev.IDA } A_{a, g}=\text { Prev. } . I D_{a, g} \times \text { Prop.IDA } A_{a, g}
$$

where $a$ is the age class, $g$ the gender, Prev.IDA the prevalence of IDA, Prev.ID the prevalence of ID and Prop.IDA the proportion of IDA due to ID in France. The data are given in Table 1.

To determine the proportion of anemias per severity (mild, moderate, severe), the level of hemoglobin of the French population was considered. Stoltzfus et al., 2004 provided hemoglobin levels in blood of children in EUR-A WHO region. The standard deviation of hemoglobin taken into account in this study was $1.0 \mathrm{~g} / \mathrm{dL}$ for countries with anemia prevalence under $15 \%$, as it is in France $[9,23]$ (see Appendix A.1 Table A1). In 2011, a study evaluated the iron status in European adolescents and found similar hemoglobin levels [27]. The following age class and hemoglobin levels were estimated from linear functions. Adult male and female hemoglobin levels were provided by Santé Publique France data from ENNS (Étude Nationale Nutrition Santé) study [26]. The methodology to determine hemoglobin levels of the French population is presented in Appendix A.1 and the levels used in the present study are given in Table 1 and in Appendix A.1 Table A2. These levels of hemoglobin followed a normal distribution from which the proportion of anemia in France (with and without ID) was estimated. 
Table 1. Sources of information and implementation of the inputs either as deterministic values or as probability distributions.

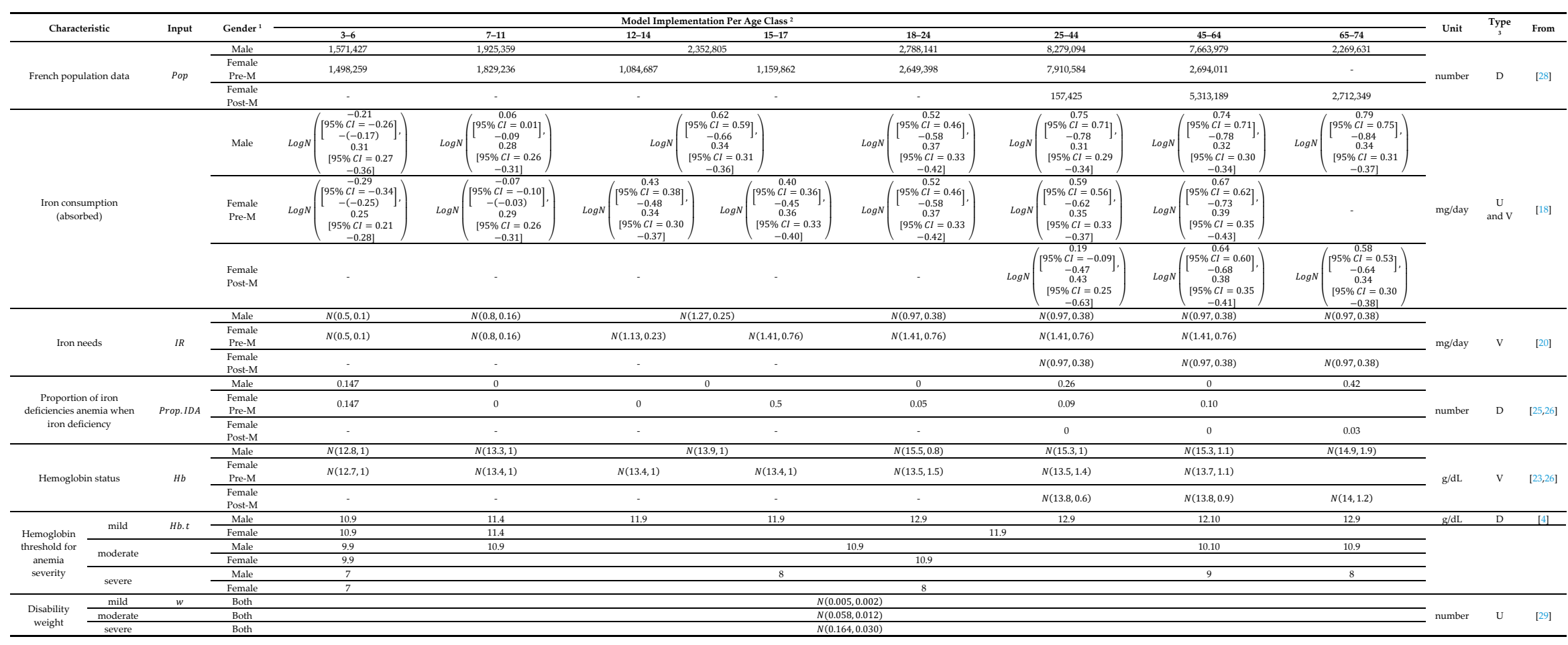

${ }^{1}$ Female Pre-M, Premenopausal females; Female Post-M, Postmenopausal females. Menstruating females considered between 15 years and 64 years at most; ${ }^{2}$ Following R parametrization;

${ }^{3} \mathrm{D}$, deterministic; V, Variability; U, uncertainty. 
According to "The burden of diseases of anemia", three levels of anemia were considered: Severe, moderate, and mild, as used by Kassebaum on the behalf of GBD 2013 Anemia Collaborators evaluation (2016) based on which health state descriptions are presented in Table 2.

Table 2. Iron deficiency anemia severity levels and health state descriptions from the Global burden of disease 2013 study [29].

\begin{tabular}{ll}
\hline Health State & Health State Description \\
\hline Mild IDA & $\begin{array}{l}\text { Feels slightly tired and weak at times, but this does not interfere with normal daily } \\
\text { activities. }\end{array}$ \\
Moderate IDA & $\begin{array}{l}\text { Feels moderate fatigue, weakness, and shortness of breath after exercise, making daily } \\
\text { activities more difficult. }\end{array}$ \\
Severe IDA & $\begin{array}{l}\text { Feels very weak, tired and short of breath, and has problems with activities that require } \\
\text { physical effort or deep concentration. }\end{array}$ \\
\hline
\end{tabular}

The prevalence of anemia per severity, $\operatorname{Prev} . I D A_{a, g, s}$, was then calculated as follows:

$$
\text { Prev.IDA } A_{a, g, s}=\text { Prev.IDA } A_{a, g} * \text { Alloc.Ane } a_{a, g, s}
$$

The allocation of anemia severity, among the anemia population, Alloc. Ane $e_{a, g, s}$, is deduced from the hemoglobin normal distribution per age class and gender $(\mathrm{Hb})$ in the French population and hemoglobin thresholds (Hb.t) defined by WHO [4]. The methodology is provided in the Appendix A Method A2. We assumed that the proportion of anemia per severity (with and without ID) in the French population was the same as for anemia only due to ID.

\subsection{Burden of Diseases from Iron Deficiency Anemia}

The burden of diseases of the outcome attributable to IDA was expressed in the number of cases and disability adjusted life years (DALY). This metric estimates an equivalent number of years in good health lost due to the outcome [30].

DALY estimation takes into account mortality by considering the YLL for the age class and gender concerned. In addition, morbidity is also included and expressed in YLD. YLD is obtained by multiplying the decrease in the quality of life, expressed by a disability weight factor due to the sequelae or the stage of the outcome, by the duration of the specific disability. The disability weight factor is estimated between 0 (perfect health state) and 1 (death), available in the GBD estimations [4,29].

DALY estimation was calculated for the French population per gender and age class and expressed per 100,000 people per year, for both outcomes.

Number of IDA per age class, gender and severity $\left(N B . I D A_{a, g, s}\right)$ was calculated, considering the number of individuals in the concerned population $\left(P_{o p}, g\right)$ :

$$
\text { NB.IDA } A_{a, g, s}=P_{0 p}, g \times \text { Prev.IDA } A_{a, g, s}
$$

Then, the number of DALY due to IDA per age class and gender $\left(D A L Y_{a, g}\right)$ was estimated as follows:

$$
D A L Y_{a, g}=\sum_{s} N B \cdot I D A_{a, g, s} \times w_{a, g, s}
$$

where $w$ was the disability weight factor.

\subsection{Second-Order Monte Carlo Simulation}

To estimate the ID prevalence, two distributions were used: Iron intake and iron needs. The iron intake distribution came from a fitting procedure with bootstrapping to separate uncertainty and variability. The iron needs' normal distribution was built using EFSA report values, it included only variability. The ID prevalence was then estimated by Monte Carlo simulation in two dimensions 
(MC2D). One thousand iterations were run to capture the uncertainty and 10,000 iterations for the variability. Note that once the ID prevalence was estimated with its uncertainty, the outputs of the model conveyed only uncertainty. To verify the stability of the outputs, three simulations were carried out for each age class and gender, a variation less than $1 \%$ for the DALY output was obtained.

\subsection{Consumption Scenarios}

To decrease ID and IDA for the most concerned population-all populations with IDA-consumption scenarios were performed by setting the consumption of a food product rich in iron, at different quantities. Red meat was chosen as food model because it is the richest source of heme-iron in developed countries [11], which is the most absorbable type of iron by human beings, with $20 \%$ to $30 \%$ of iron intake absorbed [10]. The consumption scenario was made for consumption of cooked ground beef with $15 \%$ of fat, which is the type of beef meat most consumed by the French population (51 g per week) [18], most acceptable by youngest populations and easiest to eat by elderly populations. From initial iron intake by French individuals involved in INCA 2 study, and taken into account in this study, the iron from unprocessed red meat (muscle of beef, pork, veal, horse, lamb) consumption was estimated from CIQUAL tables available at https://ciqual.anses.fr/ [31] (see Appendix A.2 Table A3). The amount of iron from red meat consumption was subtracted from the total iron intake for the consumption scenario $0 \mathrm{~g} / \mathrm{d}$ of red meat. The consumption of $25 \mathrm{~g} / \mathrm{d}, 50 \mathrm{~g} / \mathrm{d}, 75 \mathrm{~g} / \mathrm{d}, 100 \mathrm{~g} / \mathrm{d}$ of cooked ground beef $15 \%$ fat was applied, with an amount of $2.6 \mathrm{mg}$ of iron per $100 \mathrm{~g}$ of meat and an average absorption of $25 \%$ [10]. The consumption scenario took the amount of iron from other dietary sources (without red meat) and the addition of the amount of ground beef into account.

\section{Results}

\subsection{Prevalence and Number of Iron Deficiencies in France}

The distributions of ID with current consumption of iron in France are shown in Table 3. The mean number of ID cases is represented with its $95 \%$ confidence interval.

Table 3. Prevalence and number of iron deficiencies per 100,000 French individuals, per age class and gender. Mean value and its $95 \%$ confidence interval.

\begin{tabular}{|c|c|c|c|c|c|c|}
\hline \multirow{3}{*}{ Age Class } & \multirow{2}{*}{\multicolumn{2}{|c|}{ Male }} & \multicolumn{4}{|c|}{ Female } \\
\hline & & & \multicolumn{2}{|c|}{ Premenopausal } & \multicolumn{2}{|c|}{ Postmenopausal } \\
\hline & Prevalence & $\begin{array}{l}\text { Number of } \\
\text { Cases }\end{array}$ & Prevalence & $\begin{array}{l}\text { Number of } \\
\text { Cases }\end{array}$ & Prevalence & $\begin{array}{c}\text { Number of } \\
\text { Cases }\end{array}$ \\
\hline $3-6$ & $\begin{array}{c}9 \% \\
(6 \%-12 \%) \\
\end{array}$ & $220(140-310)$ & $\begin{array}{c}9 \% \\
(7 \%-13 \%)\end{array}$ & $230(160-300)$ & - & - \\
\hline $7-11$ & $\begin{array}{c}20 \% \\
(16 \%-24 \%)\end{array}$ & $620(510-730)$ & $\begin{array}{c}31 \% \\
(27 \%-36 \%)\end{array}$ & $930(810-1100)$ & - & - \\
\hline $12-14$ & \multirow{2}{*}{$\begin{array}{c}15 \% \\
(13 \%-18 \%)\end{array}$} & \multirow{2}{*}{$580(490-680)$} & $\begin{array}{c}21 \% \\
(17 \%-25 \%)\end{array}$ & $360(290-440)$ & - & - \\
\hline $15-17$ & & & $\begin{array}{c}43.7 \% \\
(41 \%-47 \%)\end{array}$ & $820(760-880)$ & - & - \\
\hline $18-24$ & $\begin{array}{c}9 \% \\
(6 \%-12 \%)\end{array}$ & $400(280-530)$ & $\begin{array}{c}37 \% \\
(33 \%-41 \%)\end{array}$ & $\begin{array}{c}1600 \\
(1400-1700)\end{array}$ & - & - \\
\hline $25-44$ & $5 \%(4 \%-7 \%)$ & $720(580-880)$ & $\begin{array}{c}32 \% \\
(30 \%-34 \%)\end{array}$ & $\begin{array}{c}4100 \\
(3900-4400)\end{array}$ & $\begin{array}{c}34 \% \\
(17 \%-50 \%)\end{array}$ & $90(40-130)$ \\
\hline $45-64$ & $4 \%(3 \%-4 \%)$ & $450(360-460)$ & $\begin{array}{c}27 \% \\
(24 \%-31 \%)\end{array}$ & $\begin{array}{c}1200 \\
(1100-1300)\end{array}$ & $\begin{array}{c}8 \% \\
(7 \%-10 \%)\end{array}$ & $\begin{array}{c}720 \\
(580-860)\end{array}$ \\
\hline $65-74$ & $\begin{array}{c}3.4 \% \\
(2 \%-5 \%)\end{array}$ & $130(80-190)$ & - & - & $\begin{array}{c}10 \% \\
(7 \%-12 \%)\end{array}$ & $\begin{array}{c}420 \\
(320-530)\end{array}$ \\
\hline
\end{tabular}


Among children, the most concerned with ID were children aged from 7 to 11 , with $20 \%$ (95\% CI $=16 \%-24 \%)$ and $31 \%(95 \% \mathrm{CI}=27 \%-36 \%)$ ID in this age class for males and females, respectively. Adolescent females were also more concerned with ID compared to adolescent males (Table 3).

The higher impact of ID among females was also noted in adults' age classes. Menstruating adult females aged from 18 to 24 were the most concerned with ID with $37 \%$ [ $95 \% \mathrm{CI}=33 \%-41 \%$ ] of iron-deficient in this population group, corresponding to 1600 [95\% CI $=1400-1700]$ IDs cases per 100,000 individuals. After this age class, the prevalence of ID decreases with increasing age.

\subsection{Number of Iron Deficiency Anemias}

In France, only children aged from three to six, older adolescent females, adult females and males aged from 25 to 44 years and from 65 to 74 suffered from IDA [25,26]. The distributions of IDA with current consumption of iron in France are shown in Table 4. The mean number of IDA cases is represented with its $95 \%$ confidence interval.

Table 4. Number of cases and disability adjusted life years (DALY) per 100,000 individuals of iron deficiencies anemias in France, per age class and gender. Mean value and its 95\% confidence interval.

\begin{tabular}{ccccccc}
\hline \multirow{2}{*}{ Age Class } & \multicolumn{2}{c}{ Male } & \multicolumn{4}{c}{ Female } \\
\cline { 2 - 6 } & \multirow{nnnyyy}{*}{$\begin{array}{c}\text { Number of } \\
\text { Cases }\end{array}$} & DALY & $\begin{array}{c}\text { Number of } \\
\text { Cases }\end{array}$ & DALY & $\begin{array}{c}\text { Number of } \\
\text { Cases }\end{array}$ & DALY \\
\hline $3-6$ & $32(21-45)$ & $0.3(0.1-0.5)$ & $33(23-45)$ & $0.3(0.1-0.5)$ & - & - \\
\hline $7-11$ & $0(0-0)$ & $0(0-0)$ & $0(0-0)$ & $0(0-0)$ & - & - \\
\hline $12-14$ & $0(0-0)$ & $0(0-0)$ & $0(0-0)$ & $0(0-0)$ & - & - \\
\hline $15-17$ & $0(0-0)$ & $0(0-0)$ & $77(69-85)$ & $1.6(1.0-2.1)$ & - & - \\
\hline $18-24$ & 183 & $0.9(0.1-1.8)$ & $\begin{array}{c}374 \\
(353-394)\end{array}$ & $6.5(4.2-9.0)$ & $0(0-0)$ & $0(0-0)$ \\
\hline $25-44$ & $(146-224)$ & $0(0-0)$ & $\begin{array}{c}122 \\
(108-136)\end{array}$ & $1.2(0.7-1.8)$ & $0(0-0)$ & $0(0-0)$ \\
\hline $45-64$ & $0(0-0)$ & $0.6(0.3-1.0)$ & - & - & $11(9-15)$ & $0.1(0.1-0.2)$ \\
\hline $65-74$ & $54(33-80)$ & & & & & - \\
\hline
\end{tabular}

A total of 1290 [95\% CI $=1230-1350]$ cases of IDA per 100,000 individuals per year was estimated in the French population.

Children aged from three to six, had almost the same number of IDA cases for males and females with $32(95 \% \mathrm{CI}=21-45)$ and $33(95 \% \mathrm{CI}=23-45)$ cases per 100,000 individuals per year, respectively. Among adolescents, only females aged from 15 to 17 are concerned with IDA. The number of IDA cases for this population was ten times higher than for females aged from three to six.

Adult females were significantly more concerned with IDA than males with $584(95 \% \mathrm{CI}=558-612)$ IDA cases versus 237 (95\% CI $=194-282)$ IDA cases per 100,000 individuals, respectively. The major number of cases concerned menstruating women aged from 15 to 17 with 404 (95\% CI =377-431) IDA cases per 100,000 individuals per year. The cases of IDA for menopaused females only concerned the last age class.

\subsection{DALY Attributable to Iron Deficiency Anemias}

The number of DALY per 100,000 individuals per year associated with IDA in France is given in Table 4 . The mean number of IDA DALY is represented with its $95 \%$ confidence interval.

The major contributors to the burden from IDA were menstruating females aged from 25 to 44 with $6.5(95 \% \mathrm{CI}=4.2-9.0)$ DALY associated with IDA per 100,000 individuals per year. Young children aged from three to six, had a low burden with an equivalent number of DALYs $(0.3(95 \% \mathrm{CI}=0.1-0.5)$ 
DALY per 100,000 per year). Older adolescent females, aged from 15 to 17, contributed with 4.0 (95\% $\mathrm{CI}=2.1-5.9)$ DALY per 100,000 individuals per year.

The estimated number of DALY associated with IDA was $16(95 \% \mathrm{CI}=11-20)$ per 100,000 French individuals per year, from which more than $80 \%$ of the DALY were attributable to menstruating females.

\subsection{Consumption Scenarios}

Based on the developed model, to estimate the effect of red meat intake on IDA burden of diseases, a consumption scenario for young children (three to six), older adolescent females (15-17), males $(25-44 ; \geq 60)$, adults menstruating females $(\geq 18)$ and menstruated females $(65-74)$ was generated. The results for young children and older adolescent females are presented in Figure 2 and results for adult females are reported in Figure 3.

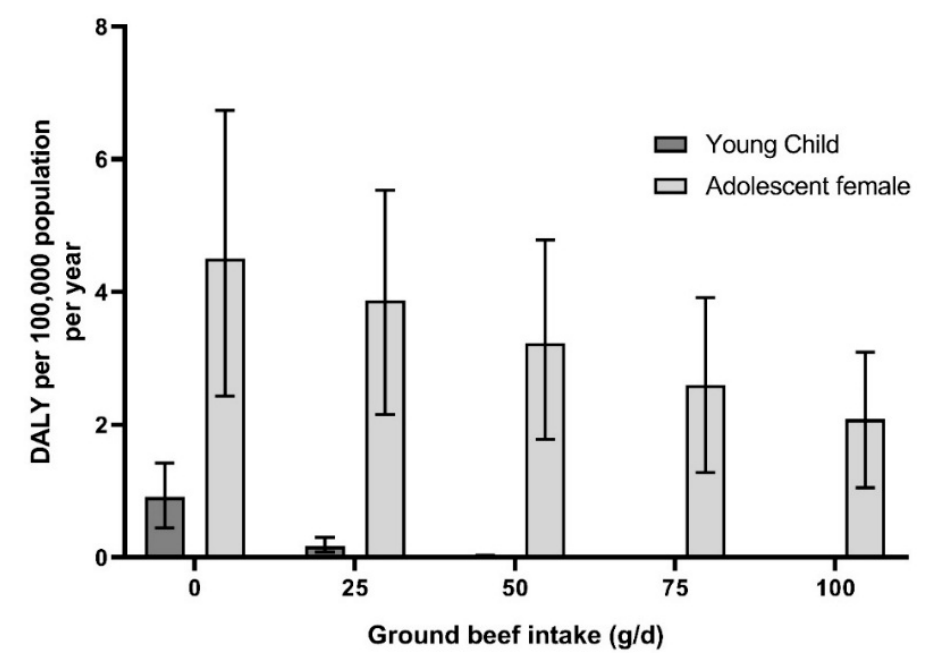

Figure 2. Estimated number of DALY from iron deficiency anemias in France for young children (three to six) and adolescent females (15-17) according to ground beef consumption scenarios. Results expressed per 100,000 individuals per year. Full lines represent the $95 \%$ uncertainty around the mean value.

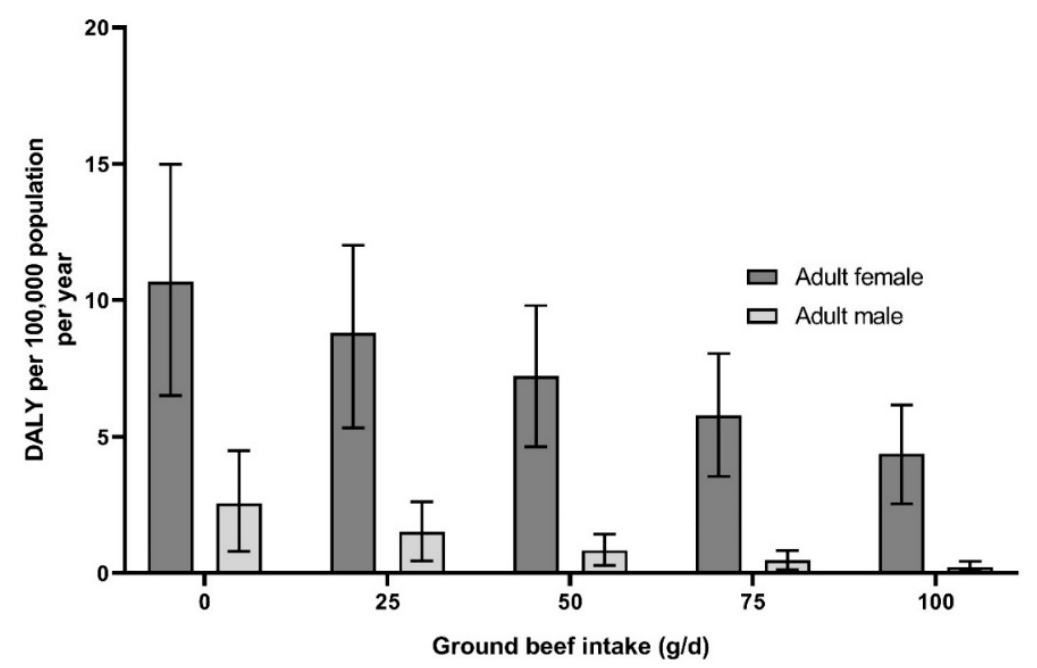

Figure 3. Estimated number of DALY from iron deficiency anemias in France for adult males and females according to ground beef consumption scenarios. Results expressed per 100,000 individuals per year. Full lines represent the $95 \%$ uncertainty around the mean value.

For young children, the consumption of $50 \mathrm{~g} / \mathrm{d}$ of ground beef, added to the iron consumption from other sources of iron without red meat, in current diet, would be enough to reduce the prevalence 
of ID to $0.2 \%$ (95\% CI $=0 \%-1.9 \%$ ) per 100,000 individuals per year and to decrease the burden of IDA close to zero DALY. For older adolescent females, the consumption of $100 \mathrm{~g} / \mathrm{d}$ of red meat-which may represent a portion of red meat per day-added to the other sources of iron in current diet, would not be enough to eliminate ID and IDA. However, it would reduce the prevalence of ID to $22 \%$ (95\% $\mathrm{CI}=0 \%-90 \%$ ) per 100,000 individuals per year and halve IDA burden when comparing with current consumption (mean red meat consumption of $18.2 \mathrm{~g} / \mathrm{d}$ ).

The burden of IDA in male adults was already low, but the consumption of $50 \mathrm{~g} / \mathrm{d}$ or $100 \mathrm{~g} / \mathrm{d}$ of red meat, in addition to the other sources of iron in current diet (without red meat), would decrease the current number of DALY from $0.8[95 \% \mathrm{CI}=0.3-1.4]$ and $0.2[95 \% \mathrm{CI}=0.1-0.4]$ per 100,000 individuals per year, respectively.

The burden of IDA in adult females aged over 18, were the highest in the population, especially for menstruating females (Figure 3). The consumption of $50 \mathrm{~g} / \mathrm{d}$ or $100 \mathrm{~g} / \mathrm{d}$ of red meat, in addition to the other sources of iron in current diet (without red meat) would decrease the current number of DALY down to $7.2(95 \% \mathrm{CI}=4.6-9.8)$ and $4.4(95 \% \mathrm{CI}=2.5-6.2)$ per 100,000 individuals per year, respectively.

\section{Discussion}

The present study objective was to build an original probabilistic assessment model to estimate the burden of diseases associated with ID and subsequently IDA with the current iron consumption. A probabilistic risk assessment model was developed to estimate the prevalence of iron deficiencies, the number of cases and DALY in France from iron consumption.

Our results were in line with a previous study in France, from 2001, especially for young children [25]. According to the study, $13.6 \%$ of young children aged from two to six were iron-deficient, which is not far from our estimations where $9 \%(95 \% \mathrm{CI}=6 \%-12 \%)$ of young boys and $9 \%(95 \% \mathrm{CI}=$ $7 \%-13 \%$ ) of young girls were iron-deficient. However, there is a missing population in this comparison. Due to the lack of consumption data, our estimations only included children aged from three to six. This estimation was also in line with iron deficiencies prevalence in Europe estimated between 7\% and $18 \%$ for toddlers and young children [32]. On the other hand, these results were higher than those found in France in a more recent study which found 3.2\% (95\% CI $=2.0 \%-5.1 \%$ ) [33], although the threshold for ID definition in this study was low with 10 or $12 \mu \mathrm{g} / \mathrm{L}$-corresponding to the total depletion of iron storage. Indeed, the definition of ID was not the same because, with the data available, it was not possible to quantify the total depletion of iron, but the iron under the average requirement. For adolescents, it was estimated 15\% (95\% CI $=13 \%-18 \%)$ ID prevalence for males aged from 12 to 17 years old and $21 \%(95 \% \mathrm{CI}=17 \%-25 \%)$ and $44 \%(95 \% \mathrm{CI}=41 \%-47 \%)$ ID prevalence for adolescent females aged from 12 to 14 and from 15 to 17, respectively. This was in line with the estimations in Europe (between $0 \%$ and $43 \%$ ) but was higher than iron deficiencies estimated for French adolescents ( $0 \%$ for males aged from 14 to $18,3.1 \%$ for females aged from 11 to 15 and $15.4 \%$ for females aged from 14 to 18) [24]. Nonetheless comparison was hard to establish because age classes were not the same as those in this study, the data were from 1988 and the definition of ID threshold was not the same [34]. For the adult population, the most concerned with ID were menstruating adult females. This is mainly because iron losses are higher than for males and menopausal females, then, iron needs are higher for menstruating females $(1.41 \mathrm{mg} /$ day) compared to other adults' needs $(0.97 \mathrm{mg} /$ day $)$. In addition, iron consumption by adult menstruating females (mean $11 \mathrm{mg} / \mathrm{d}, \mathrm{sd} 4 \mathrm{mg} / \mathrm{d}$ ) was lower than by adult males (mean $14 \mathrm{mg} / \mathrm{d}$, sd $5 \mathrm{mg} / \mathrm{d}$ ). The values estimated in our study were similar to those measured in blood of French adults in ENNS study (for serum ferritin $\leq 30 \mu \mathrm{g} / \mathrm{L}$ ) [35].

The estimated number of IDA cases was $1290(95 \% \mathrm{CI}=1130-1350)$ IDA per 100,000 individuals per year (Table 4) with $584(95 \%$ CI $=558-612)$ cases per 100,000 people for adult women per year. This corresponded to $797,200(95 \% \mathrm{CI}=759,900-836,900)$ for the French population per year. The major contributors were menstruating females aged from 15 to 17 . Indeed, twenty-two percent of older adolescent females were identified with IDA in our study, which was higher than the results found in 1994 in France (7.4\% for adolescents aged from 14 to 18) [24,34]. The relevance of this comparison is 
somewhat questionable as there is a substantial time difference between the two studies: 2007 versus 1994. For adult females, it was estimated $1.7 \%(95 \% \mathrm{CI}=1.6 \%-1.8 \%)$ of IDA in France which was lower than results obtained in the SUpplementation en VItamines et Minéraux AntioXydants (SU.VI.MAX) study (4.4\%) [36]. However, the latter study only included individuals aged from 35 to 60 years old.

To go further than the estimation of the prevalence and the number of cases, we have taken into account morbidity with the use of the composite metric DALY [37,38], which is the most used in risk and benefit assessment studies [30,39]. Here, only morbidity was considered, because there is no existing data about IDA fatalities in France. Three levels of IDA severity were taken into account: Mild, moderate, and severe. The sequelae (Table 2) of the different levels of IDA were assumed to be the same whatever the sub-population, and were based on the health status definitions from the GBD study [29]. This assumption may induce an underestimation of the IDA burden for children and adolescents. Indeed, GBD health status does not take into account possible disabilities such as neurodevelopment delay due to ID and IDA which may induce impaired learning abilities, memory skills, and behavioral issues $[40,41]$. The majority of the studies evaluating the beneficial effect of iron supplementation were carried out in children under three years old. However, this age is considered under our first age class. After this age, some studies found a beneficial effect of iron treatment in older anemic children on intelligence quotient, but not in non-anemic [42]. Moreover, there was no improvement in other disabilities, such as academic achievement, memory, or motor development [42]. Therefore, experts remain cautious about these conclusions and more studies are needed to conclude about this effect. The estimated DALY of IDA cases was $16(95 \% \mathrm{CI}=11-20)$ per 100,000 people per year (Table 4) which corresponds to $9580(95 \%$ CI = 7050-12,250) DALY for the French population per year. These values were lower than, but of the same order of magnitude as the estimation by GBD's study which reported 35 DALY per 100,000 French population in 2007 [43]. The major contributors to the burden were females aged from 25 to 44 and no longer adolescent girls aged from 15 to 17 . This was due to the higher prevalence of moderate and severe anemia cases in the adult age class. However, our estimations were underestimated because children under three years old and pregnant females, which are particularly vulnerable populations, were excluded from the study $[4,5]$.

The quantification of variability and uncertainties, as recommended by international organizations [44], took into account the fitted distribution of iron intake and disability weight. For the first input cited, uncertainty and variability were quantified separately. However, for the second input cited, this separation was not possible. Even if some classify it as only variability [45] - the confidence interval representing the variability of the severity of the disability -we decided to classify it as only uncertainty as done by the majority of the previous studies $[46,47]$. The variability of the iron needs and hemoglobin status were also taken into account in the study.

Nonetheless, despite the inherent uncertainty and variability described above, the results obtained in this study can be interpreted as showing that some differences in the burden of disease were observed, such as between males and females, or between menopausal and menstruating females.

The use of DALY metric also enabled to make consumption scenarios for concerned populations. Due to the richest source of heme-iron - which is the form of iron most absorbable by humans-brought by red meat consumption [11], ground beef was taken as a food item in intake scenarios. In addition, consumption of red meat was found to increase the level of serum ferritin in the blood [12,13]. It was estimated that for young children, $50 \mathrm{~g} / \mathrm{d}$ of ground beef-corresponding to $1.3 \mathrm{mg}$ of iron-added to the other sources of iron already present in current diet (without red meat), would be enough to almost eliminate the IDA burden. For females aged over 15 years old and adult males, the consumption of $100 \mathrm{~g} / \mathrm{d}$ of ground beef-corresponding to $2.6 \mathrm{mg}$ of iron-added to the other sources of iron already present in current diet (without red meat) would not be enough to eliminate IDA burden (Figure 2; Figure 3). These results were in line with French Pediatric Society recommendations of eating $100-150 \mathrm{~g} / \mathrm{d}$ of meat for children under six years old who stopped increasing milk consumption and twice a day by children over seven years and adolescents [10], since beef meat, which has the highest level of heme-iron, is not the only meat consumed. The amount required to suppress IDA for adults 
is above the French Agency for Food, Environmental and Occupational Health and Safety (ANSES) recommendations, especially for adult women, which is to consume less than $500 \mathrm{~g}$ per week of red meat [48]. This recommendation was largely based on the conclusions of the World Cancer Research Found/Imperial College of London and the WHO, which classified red meat as "probably carcinogenic to humans" for colorectal cancer $[49,50]$. In addition, a recent study of our team determined that the consumption of over $65 \mathrm{~g} / \mathrm{d}$ of red meat would increase the risk of cardiovascular disease for the most concerned populations (adult population, especially elderly) [51]. Indeed, heme-iron, is suspected to be the main component in the mechanism associated with colorectal cancer $[52,53]$ and cardiovascular disease [54-56]. These latter health effects were not considered to be of concern for children and adolescents for whom current epidemiological data were available [57], but more studies and meta-analysis are needed to confirm this lack of association.

Furthermore, the intake scenario in this study does not consider the substitution and the acceptability of red meat. Indeed, when the individual increases the consumption of one food item, he/she may reduce the consumption of other foods. In addition, some population group will not accept to consume more red meat due to organoleptic reasons, beliefs, or ethics (e.g., vegetarian diet). In these cases, other sources of iron can be considered to reduce ID and IDA. The consumption of iron-rich sources such as white beans ( $7.97 \mathrm{mg}$ of iron per $100 \mathrm{~g}$ ), breakfast cereals $(7.03 \mathrm{mg}$ of iron per $100 \mathrm{~g})$, or lentils (6.51 mg of iron per $100 \mathrm{~g}$ ) [31] would be a possible solution, especially for adult populations with a risk of colorectal and cardiovascular disease. Nevertheless, the quantity consumed of these other sources of iron, which are in form of non heme-iron, should be higher than that needed for red meat, because the degree of absorption is lower than for heme-iron products. Otherwise, some other heme-iron containing products, such as fish and poultry have a lower proportion of iron in the food compared to red meat. Some studies show that the vegetarian and vegan population presented a higher risk of iron deficiencies [58-60]. However, there are large variations of non heme-iron absorption $(0.7 \%-22.9 \%)$. Indeed, when blood levels had low serum and plasma ferritin concentrations, the absorption of iron increased [61]. In addition, dietary enhancers (e.g., ascorbic acid, alcohol) and inhibitors (e.g., calcium, tannins, and polyphenols) influence the absorption of non heme-iron [62].

Another possible solution for ID decrease is iron supplementation. It was observed that early iron supplementation of low birth weight infants would reduce the prevalence of behavioral problems and linear growth [3]. Another study showed that iron supplementation with vitamin C of IDA children aged from 6 to 12 in Turkey, increased the intelligence quotient by 4.8 points [63]. It was shown to improve learning and memory in non-anemic ID adolescent girls, in adults with IDA, and that iron supplementation can partially reverse the effects on cognitive performance.

\section{Conclusions}

The burden of the consumption of iron has been estimated and expressed in terms of prevalence, number of cases, and DALY. The study estimated 13,630 (95\% CI $=5740-23,510)$ ID cases per 100,000 individuals per year. In terms of IDA, this corresponded to $1,290(95 \% \mathrm{CI}=1230-1350)$ IDA cases per 100,000 people per year and to $16(95 \% \mathrm{CI}=11-20)$ DALY per 100,000 individuals per year. In a further study, the IDA burden estimated here in terms of DALY will be balanced with other risks of iron-rich food intake, such as red meat. Indeed, for children and adolescents, the benefit of decreasing iron deficiency anemia can be compared with risks due to microbiological foodborne illnesses when eating red meat [64]. In addition to this latter risk, for adult populations, colorectal cancer and cardiovascular diseases attributable to red meat consumption $[51,65]$ will be also considered in this overall risk-benefit assessment.

Author Contributions: Investigation, J.D.O.M.; conceptualization, J.M.M., F.P.; methodology, J.D.O.M., J.M.M., and P.T.; software, J.D.O.M. and J.M.M.; formal analysis, J.D.O.M.; validation, P.T.; supervision, F.P., J.M.M. and S.G.; writing_-original draft, J.D.O.M.; writing—review \& editing, J.D.O.M., J.M.M., F.P. and S.G.; funding acquisition, J.M.M. 
Funding: This research was funded by Microbiologie et chaîne alimentaire department from the Institut National de la Recherche Agronomique and Région Pays de la Loire, grant number 34000653.

Acknowledgments: We acknowledge the “Equipe de Surveillance et d'Epidémiologie Nutritionnelle (Esen), équipe mixte de Santé publique France et de l'Université Paris 13", as the main investigator of the ENNS study and for the supply of results and the "Centres d'examen de santé de la Caisse nationale d'assurance maladie des travailleurs salariés (CnamTS) and their laboratories", for the determination of hemoglobin and ferritinemia.

Conflicts of Interest: The authors declare no conflict of interest. The funders had no role in the design of the study; in the collection, analyses, or interpretation of data; in the writing of the manuscript, or in the decision to publish the results.

\section{Appendix A}

Appendix A.1 Determination of the Hemoglobin Status in the Population

Table A1. Hemoglobin levels values of French population expressed in mean and (standard deviation) extracted from Stoltzfus et al. (2004) and Santé Publique France 2006-2007.

\begin{tabular}{|c|c|c|c|}
\hline Age Class & Gender (and Status) & Hemoglobin (g/dL) & Reference \\
\hline \multirow{2}{*}{$0-4$} & Male & $12.5(1)$ & \multirow{6}{*}{ [23] } \\
\hline & Female & $12.5(1)$ & \\
\hline \multirow{2}{*}{$5-14$} & Male & $13.4(1)$ & \\
\hline & Female & $13.4(1)$ & \\
\hline \multirow{2}{*}{$15-29$} & Male & $14.6(1)$ & \\
\hline & Female & $13.4(1)$ & \\
\hline \multirow{2}{*}{$18-24$} & Male & $15.5(0.8)$ & \multirow{10}{*}{ [26] } \\
\hline & Female (Premenopausal) & $13.5(1.5)$ & \\
\hline \multirow{3}{*}{$25-44$} & Male & $15.3(1)$ & \\
\hline & Female (Premenopausal) & $13.5(1.4)$ & \\
\hline & Female (Postmenopausal) & $13.8(0.6)$ & \\
\hline \multirow{3}{*}{$45-64$} & Male & $15.3(1.1)$ & \\
\hline & Female (Premenopausal) & $13.7(1.1)$ & \\
\hline & Female (Postmenopausal) & $13.8(0.9)$ & \\
\hline \multirow{2}{*}{$65-74$} & Male & $14.9(1.9)$ & \\
\hline & Female (Postmenopausal) & $14(1.2)$ & \\
\hline
\end{tabular}

The levels of hemoglobin for the age classes under 18 years old (Table A1), did not correspond to the age classes used in this study. To determine hemoglobin status for the age classes 3-6, 7-11, 12-17 for male and 12-14 and 15-17 for females, the values were determined from linear functions, established from Stoltzfus et al. (2004) hemoglobin levels from Table A1.

Two linear functions were assumed to determine hemoglobin levels for females and one linear function for males aged under 18 years old:

- To determine female hemoglobin level in the age class three to six years old, the linear function was expressed:

$$
H b_{a, g}=0.1173 \times \text { mean age of the class }+12.275
$$

- For females, age class from 7 to 11 and from 12 to 17 years old, the average hemoglobin levels were similar and estimated by the fallow function:

$$
H b_{a, g}=-0.0015 \times \text { mean age of the class }+13.413
$$


- To determine male hemoglobin level in the age class 3-6, 7-11, and 12-17 years old, the linear function was expressed:

$$
H b_{a, g}=0.1058 \times \text { mean age of the class }+12.331
$$

Hemoglobin distribution for each age class was assumed to follow a normal distribution. To determine the mean standard deviation for age classes under 18 years old, the standard deviation of hemoglobin considered in this study was the same as used by Stoltzfus et al. (2004) for countries with anemia prevalence under $15 \%(1.0 \mathrm{~g} / \mathrm{dL})[9,23]$. For older age classes, the standard deviation was estimated from ENNS study mean and confidence interval.

The levels of hemoglobin used in the present study is given in Table A2.

Table A2. Hemoglobin levels of the French population expressed in mean and (standard deviation) used in the present study.

\begin{tabular}{ccc}
\hline Age Class & Gender (and Status) & Hemoglobin (g/dL) \\
\hline \multirow{2}{*}{$3-6$} & Male & $12.8(1)$ \\
& Female & $12.7(1)$ \\
\hline \multirow{2}{*}{$7-11$} & Male & $13.3(1)$ \\
& Female & $13.4(1)$ \\
\hline $12-17$ & Male & $13.9(1)$ \\
$12-14$ & Female & $13.4(1)$ \\
$15-17$ & Female (Premenopausal) & $13.4(1)$ \\
\multirow{2}{*}{$18-24$} & Male & $15.5(0.8)$ \\
& Female (Premenopausal) & $13.5(1.5)$ \\
\hline \multirow{2}{*}{$25-44$} & Male & $15.3(1)$ \\
& Female (Premenopausal) & $13.5(1.4)$ \\
& Female (Postmenopausal) & $13.8(0.6)$ \\
\hline \multirow{2}{*}{$45-64$} & Male & $15.3(1.1)$ \\
& Female (Premenopausal) & $13.7(1.1)$ \\
& Female (Postmenopausal) & $13.8(0.9)$ \\
\hline \multirow{2}{*}{$65-74$} & Male & $14.9(1.9)$ \\
& Female (Postmenopausal) & $14(1.2)$ \\
\hline \multirow{2}{*}{5} & &
\end{tabular}

Appendix A.2 Determining the Proportion of Anemia per Severity

To determine the proportion of anemia (Ane) per age class $(a)$, gender $(g)$, and severity $(\mathrm{s})$, pnorm function was used from R software, considering hemoglobin distribution per age class and gender $(\mathrm{Hb})$ in the French population (Table A2) and hemoglobin thresholds defined by WHO (Table 1) to define anemia per severity $(H b . t)$.

- Proportion of severe anemias:

$$
\text { Ane } e_{a, g, s=\text { severe }}=\operatorname{pnorm}\left[H b . t_{s=\text { severe, }} \text { mean }\left(H b_{a, g}\right) \text {, standard deviation }\left(H b_{a, g}\right)\right]
$$

- Proportion of moderate anemias:

$$
\begin{aligned}
& \text { Ane } e_{a, g, s=\text { moderate }}=\text { pnorm }\left[H b . t_{s=\text { moderate, }} \text { mean }\left(H b_{a, g}\right), \text { standard deviation }\left(H b_{a, g}\right)\right]- \\
& \text { Ane } a, g, s=\text { severe }
\end{aligned}
$$


- Proportion of mild anemias:

$$
\begin{aligned}
\text { Ane }_{a, g, s=\text { mild }}= & \text { pnorm }\left[H b . t_{s=\text { mild }}, \text { mean }\left(H b_{a, g}\right), \text { standard deviation }\left(H b_{a, g}\right)\right] \\
& -\left(\text { Ane }_{a, g, s=\text { severe }}+\text { Ane } e_{a, g, s=\text { moderate }}\right)
\end{aligned}
$$

- Allocation of anemia severity, among the anemia population

$$
\text { Alloc.Ane } e_{a, g, s}=\frac{\text { Ane }_{a, g, s}}{\sum \text { Ane }_{a, g, s}}
$$

Table A3. Quantities of iron in different types of red meat.

\begin{tabular}{cc}
\hline Red Meat Type & Iron $\mathbf{( m / 1 0 0 ~} \mathbf{g})$ \\
\hline Cooked bourguignon beef & 4.3 \\
Cooked stew beef & 4.3 \\
Roasted horse meat & 3.4 \\
Roasted beef & 3.1 \\
Cooked ground beef $5 \%$ fat & 2.83 \\
Cooked ground beef 10\% fat & 2.71 \\
Braised beef & 5.9 \\
Raw ground beef 5\% fat & 2.65 \\
Cooked ground beef 15\% fat & 2.6 \\
Grilled entrecote beef & 2.55 \\
Cooked ground beef 20\% fat & 2.48 \\
Roast beef ribbon & 2.4 \\
Burgundy fondue & 2.3 \\
Beef grilled steak & 2.21 \\
Roasted lamb shoulder & 2.2 \\
Cooked dumplings beef & 2.2 \\
Beef carpaccio & 1.89 \\
Unspecified cooked meat & 1.77 \\
Mixed skewer of meat & 1.77 \\
Other meat & 1.77 \\
Lamb skewer & 1.73 \\
Beef skewer & 1.41 \\
Roast lamb & 1.4 \\
Cooked veal side & 1.3 \\
Roasted lean pork tenderloin & 1.29 \\
Grilled lamb chop & 1.27 \\
Braised ribs & 1.2 \\
Breaded veal cutlet & 1.11 \\
Roasted loin pork & 1.09 \\
Cooked escalope veal & 1 \\
Simmered veal & 0.95 \\
Roasted tenderloin veal & 0.87 \\
Roasted veal & 0.87 \\
Grilled pork chop & 0.84 \\
Roasted pork & 0.64 \\
\hline
\end{tabular}

\section{References}

1. WHO/CDC. Assessing the Iron Status of Populations: Including Literature Reviews; WHO/CDC: Geneva, Switzerland, 2004; p. 112.

2. WHO/UNICEF/UNU. Iron Deficiency Anaemia: Assessment, Prevention and Control, a Guide for Programme Managers; World Health Organization: Geneva, Switzerland, 2001. 
3. Jáuregui-Lobera, I. Iron deficiency and cognitive functions. Neuropsychiatr. Dis. Treat. 2014, 10, $2087-2095$. [CrossRef] [PubMed]

4. Kassebaum, N.J.; on behalf of GBD 2013 Anemia Collaborators. The global burden of anemia. Hematol. Oncol. Clin. N. Am. 2016, 30, 247-308. [CrossRef] [PubMed]

5. WHO/CDC. Worldwide Prevalence of Anaemia 1993-2005: WHO Global Database on Anaemia; WHO/CDC: Geneva, Switzerland, 2008; p. 51.

6. Olives, J.P. Causes des déficits en fer chez l'enfant. Arch. Pédiatrie 2017, 24, 5S2-5S5. [CrossRef]

7. Dignass, A.; Farrag, K.; Stein, J. Limitations of Serum Ferritin in Diagnosing Iron Deficiency in Inflammatory Conditions. Int. J. Chronic Dis. 2018, 2018, 1-11. [CrossRef] [PubMed]

8. Soppi, E.T. Iron deficiency without anemia-A clinical challenge. Clin. Case Rep. 2018, 6, 1082-1086. [CrossRef] [PubMed]

9. Stoltzfus, R.J. Iron deficiency: Global prevalence and consequences. Food Nutr. Bull. 2003, 24, S99-S103. [CrossRef] [PubMed]

10. Tounian, P.; Chouraqui, J.P. Iron in nutrition. Arch. Pediatr. 2017, 24, 5s23-25s31. [CrossRef]

11. Czerwonka, M.; Tokarz, A. Iron in red meat-friend or foe. Meat Sci. 2017, 123, 157-165. [CrossRef] [PubMed]

12. Moshe, G.; Amitai, Y.; Korchia, G.; Korchia, L.; Tenenbaum, A.; Rosenblum, J.; Schechter, A. Anemia and iron deficiency in children: Association with red meat and poultry consumption. J. Pediatr. Gastroenterol. Nutr. 2013, 57, 722-727. [CrossRef]

13. Szymlek-Gay, A.E.; Ferguson, E.L.; Heath, A.L.M.; Gray, A.R.; Gibson, R.S.; Heath, A.L.M. Food-based strategies improve iron status in toddlers: A randomized controlled trial. Am. J. Clin. Nutr. 2009, 90, 1541-1551. [CrossRef]

14. WHO. Health Statistics and Information Systems: About the Global Burden of Disease (GBD) Project. Available online: http://www.who.int/healthinfo/global_burden_disease/about/en/ (accessed on 5 April 2018).

15. Cummins, E. Fundamental Principles of Risk Assessment. In Textbook on Quantitative Tools for Sustainable Food and Energy in the Food Chain; Geril, P., Ed.; EUROSIS: Ghent, Belgium, 2017; Volume 1, pp. 151-179.

16. Thompson, K.M. Variability and Uncertainty Meet Risk Management and Risk Communication. Risk Anal. 2002, 22, 647-654. [CrossRef] [PubMed]

17. Cummins, E. Quantifying Microbial Propagation. In Modeling in Food Microbiology; Membré, J.M., Vasilis, V., Eds.; Elsevier: Oxford, UK, 2016; pp. 17-31.

18. ANSES. Données de Consommations et Habitudes Alimentaires de L'étude INCA 2. Available online: https://www.data.gouv.fr/fr/datasets/donnees-de-consommations-et-habitudes-alimentaires-deletude-inca-2-3/\#_ (accessed on 23 August 2017).

19. Inserm. Ménopause: Améliorer la Sécurité D’utilisation des Traitements Hormonaux. Available online: https://www.inserm.fr/information-en-sante/dossiers-information/menopause (accessed on 1 June 2019).

20. EFSA Panel on Dietetic Products Nutrition Allergies. Scientific opinion on dietary reference values for iron. EFSA J. 2015, 13, 4254. [CrossRef]

21. Norden. Nordic Nutrition Recommendations 2012: Integrating Nutrition and Physical Activity; Nordic Council of Ministers: Copenhagen, Denmark, 2014; p. 627.

22. Ined. L'âge aux Premières Règles. Available online: https://www.ined.fr/fr/tout-savoir-population/memosdemo/focus/l-age-aux-premieres-regles/ (accessed on 20 June 2019).

23. Stoltzfus, R.J.; Mullany, L.; Black, R.E. Iron Deficiency Anaemia; WHO: Geneva, Switzerland, 2004; pp. $163-209$.

24. Hercberg, S.; Preziosi, P.; Galan, P. Iron deficiency in Europe. Public Health Nutr. 2001, 4, 537-545. [CrossRef] [PubMed]

25. Hercberg, S.; Cailhol, J.; Franchisseur, C.; Maurel, M. La dificience en fer et l'anémie ferriprive dans la population française. Rev. Française Lab. 2001, 334, 55-58. [CrossRef]

26. Santé Publique France-Université Paris 13. ENNS: Étude Nationale Nutrition Santé; Santé Publique France: Saint-Maurice, France, 2006-2007.

27. Ferrari, M.; Mistura, L.; Patterson, E.; Sjöström, M.; E Díaz, L.; Stehle, P.; Gonzalez-Gross, M.; Kersting, M.; Widhalm, K.; Molnár, D.; et al. Evaluation of iron status in European adolescents through biochemical iron indicators: The HELENA Study. Eur. J. Clin. Nutr. 2011, 65, 340-349. [CrossRef] [PubMed]

28. Insee. Projections de population 2007-2060 pour la France métropolitaine: Projections de population-Insee Résultats; Insee: Paris, France, 2010. 
29. Salomon, A.J.; Haagsma, A.J.; Davis, A.; De Noordhout, C.M.; Polinder, S.; Havelaar, A.H.; Cassini, A.; Devleesschauwer, B.; Kretzschmar, M.; Speybroeck, N.; et al. Disability weights for the Global Burden of Disease 2013 study. Lancet Glob. Health 2015, 3, e712-e723. [CrossRef]

30. Hoekstra, J.; Hart, A.; Boobis, A.; Claupein, E.; Cockburn, A.; Hunt, A.; Knudsen, I.; Richardson, D.; Schilter, B.; Schütte, K.; et al. BRAFO tiered approach for benefit-risk assessment of foods. Food Chem. Toxicol. 2012, 50, S684-S698. [CrossRef]

31. ANSES. Ciqual: Table de Composition Nutritionelle des Aliments. Available online: https://ciqual.anses.fr/ (accessed on 29 May 2019).

32. Dupont, C. Prévalence de la carence en fer. Arch. Pédiatrie 2017, 24, 5S45-5S48. [CrossRef]

33. Sacri, A.S.; Hercberg, S.; Gouya, L.; Levy, C.; Bocquet, A.; Blondel, B.; Vincelet, C.; Hebel, P.; Vinatier, I.; Montalembert, M.; et al. Very low prevalence of iron deficiency among young French children: A national cross-sectional hospital-based survey. Matern. Child Nutr. 2018, 14, e12460. [CrossRef]

34. Preziosi, P.; Hercberg, S.; Galan, P.; Devanlay, M.; Cherouvrier, F.; Dupin, H. Iron Status of a Healthy French Population: Factors Determining Biochemical Markers. Ann. Nutr. Metab. 1994, 38, 192-202. [CrossRef]

35. InVS. Marqueurs Biologiques de L'état Nutritionnel-Adultes 18-74 Ans: Tableaux de Distribution-Etude Nationale Nutrition Santé (ENNS). Available online: https://www.santepubliquefrance.fr/content/download/ 56036/file/etat-nutritionnel-adultes-vitamines-12.pdf (accessed on 30 August 2019).

36. Galan, P.; Yoon, H.C.; Preziosi, P.; Viteri, F.; Valeix, P.; Fieux, B.; Briançon, S.; Malvy, D.; Roussel, A.M.; Favier, A.; et al. Determining factors in the iron status of adult women in the SU.VI.MAX study. SUpplementation en VItamines et Minéraux AntioXydants. Eur. J. Clin. Nutr. 1998, 52, 383-388. [CrossRef] [PubMed]

37. Pires, S.M.; Boué, G.; Boobis, A.; Eneroth, H.; Hoekstra, J.; Membré, J.M.; Persson, I.M.; Poulsen, M.; Ruzante, J.; Van Klaveren, J.; et al. Risk Benefit Assessment of foods: Key findings from an international workshop. Food Res. Int. 2019, 116, 859-869. [CrossRef] [PubMed]

38. Murray, C.J. Quantifying the burden of disease: The technical basis for disability-adjusted life years. Bull. World Health Organ. 1994, 72, 429-445. [PubMed]

39. Nauta, M.J.; Andersen, R.; Pilegaard, K.; Pires, S.M.; Ravn-Haren, G.; Tetens, I.; Poulsen, M. Meeting the challenges in the development of risk-benefit assessment of foods. Trends Food Sci. Technol. 2018, 76, 90-100. [CrossRef]

40. Vallee, L. Iron and Neurodevelopment. Arch. Pediatr. 2017, 24, 5S18-5S22.

41. Tseng, M. Dietary Patterns and Prostate Cancer Risk in the National Health and Nutrition Examination Survey Epidemiological Follow-up Study Cohort. Cancer Epidemiol. Biomark. Prev. 2004, 13, 71-77. [CrossRef]

42. Larson, L.M.; Phiri, K.S.; Pasricha, S.-R. Iron and Cognitive Development: What Is the Evidence? Ann. Nutr. Metab. 2017, 71, 25-38. [CrossRef]

43. IHME. GBD Compare/Viz Hub. Available online: https://vizhub.healthdata.org/gbd-compare/ (accessed on 22 April 2019).

44. FAO/WHO; Codex Alimentarius Commission. Principles and Guidelines for the Conduct of Microbiological Risk Assessment; FAO: Rome, Italy, 1999; pp. 1-5.

45. Havelaar, A.H.; Van Duynhoven, Y.T.H.P.; Nauta, M.; Bouwknegt, M.; Heuvelink, A.E.; De Wit, G.A.; Nieuwenhuizen, M.G.M.; Van De Kar, N.C.A.J. Disease burden in The Netherlands due to infections with Shiga toxin-producing Escherichia coli O157. Epidemiol. Infect. 2004, 132, 467-484. [CrossRef]

46. Boué, G.; Cummins, E.; Guillou, S.; Antignac, J.; Le Bizec, B.; Membré, J. Development and Application of a Probabilistic Risk-Benefit Assessment Model for Infant Feeding Integrating Microbiological, Nutritional, and Chemical Components. Risk Anal. 2017, 37, 2360-2388. [CrossRef]

47. Thomsen, S.T.; Pires, S.M.; Devleesschauwer, B.; Poulsen, M.; Fagt, S.; Ygil, K.H.; Andersen, R. Investigating the risk-benefit balance of substituting red and processed meat with fish in a Danish diet. Food Chem. Toxicol. 2018, 120, 50-63. [CrossRef]

48. ANSES. Avis et rapport Relatifs à L'actualisation des Repères du PNNS: Révision des Repères de Consommation Alimentaires; ANSES: Maisons-Alfort, France, 2016; pp. 1-192.

49. WCRF/AICR. Diet, Nutrition, Physical Activity and Colorectal Cancer; WCRF/AICR: Washington, DC, USA, 2017; pp. 1-109.

50. Bouvard, V.; Loomis, D.; Guyton, K.Z.; Grosse, Y.; El Ghissassi, F.; Benbrahim-Tallaa, L.; Guha, N.; Mattock, H.; Straif, K. Carcinogenicity of consumption of red and processed meat. Lancet Oncol. 2015, 16, 1599-1600. [CrossRef] 
51. Mota, J.D.O.; Boué, G.; Guillou, S.; Pierre, F.; Membré, J.M. Estimation of the burden of disease attributable to red meat consumption in France: Influence on colorectal cancer and cardiovascular diseases. Food Chem. Toxicol. 2019, 130, 174-186. [CrossRef] [PubMed]

52. Bastide, N.; Morois, S.; Cadeau, C.; Kangas, S.; Serafini, M.; Gusto, G.; Dossus, L.; Pierre, F.H.; Clavel-Chapelon, F.; Boutron-Ruault, M.C. Heme iron intake, dietary antioxidant capacity, and risk of colorectal adenomas in a large cohort study of French women. Cancer Epidemiol. Biomark. Prev. 2016, 25, 640-647. [CrossRef] [PubMed]

53. Bastide, N.M.; Chenni, F.; Audebert, M.; Santarelli, R.L.; Naud, N.; Baradat, M.; Jouanin, I.; Surya, R.; Hobbs, D.A.; Kuhnle, G.; et al. A Central Role for Heme Iron in Colon Carcinogenesis Associated with Red Meat Intake. Cancer Res. 2015, 75, 870-879. [CrossRef] [PubMed]

54. Ascherio, A.; Willett, W.C.; Rimm, E.B.; Giovannucci, E.L.; Stampfer, M.J. Dietary iron intake and risk of coronary disease among men. Circulation 1994, 89, 969-974. [CrossRef] [PubMed]

55. Qi, L.; van Dam, R.M.; Rexrode, K.; Hu, F.B. Heme iron from diet as a risk factor for coronary heart disease in women with type 2 diabetes. Diabetes Care 2007, 30, 101-106. [CrossRef] [PubMed]

56. Sullivan, J. Iron and the sex difference in heart disease risk. Lancet 1981, 317, 1293-1294. [CrossRef]

57. ANSES. Avis de L'AGENCE Nationale de Sécurité Sanitaire de L'alimentation, de L'environnement et du Travail Relatif à L'actualisation des Repères Alimentaires du PNNS Pour les Enfants de 4 à 17 Ans; ANSES: Maisons-Alfort, France, 2019; pp. 1-41.

58. Nelson, M.; White, J.; Rhodes, C. Haemoglobin, ferritin, and iron intakes in British children aged 12-14 years: A preliminary investigation. Br. J. Nutr. 1993, 70, 147-155. [CrossRef]

59. Donovan, U.M.; Gibson, R.S. Iron and zinc status of young women aged 14 to 19 years consuming vegetarian and omnivorous diets. J. Am. Coll. Nutr. 1995, 14, 463-472. [CrossRef]

60. Alexander, D.; Ball, M.J.; Mann, J. Nutrient intake and haematological status of vegetarians and age-sex matched omnivores. Eur. J. Clin. Nutr. 1994, 48, 538-546.

61. Collings, R.; Harvey, L.J.; Hooper, L.; Hurst, R.; Brown, T.J.; Ansett, J.; King, M.; Fairweather-Tait, S.J. The absorption of iron from whole diets: A systematic review. Am. J. Clin. Nutr. 2013, 98, 65-81. [CrossRef] [PubMed]

62. Hurrell, R.; Egli, I. Iron bioavailability and dietary reference values. Am. J. Clin. Nutr. 2010, 91, 1461S-1467S. [CrossRef] [PubMed]

63. Agaoglu, L.; Torun, O.; Unuvar, E.; Sefil, Y.; Demir, D. Effects of iron deficiency anemia on cognitive function in children. Arzneimittelforschung 2007, 57, 426-430. [CrossRef] [PubMed]

64. ECDC/EFSA. The European Union Summary Report on Trends and Sources of Zoonoses, Zoonotic Agents and Food-Borne Outbreaks in 2017; European Food Safety Authority: Parma, Italy, 2018; p. 262.

65. Mota, J.D.O.; Tounian, P.; Guillou, S.; Pierre, F.; Membré, J.-M. Risque et bénéfice nutritionnels associés à la consommation de viande rouge en France. Nutr. Clin. Métabolisme 2019, 33, 109. [CrossRef] 